\title{
A Comparative Study On The Effect Of Telephone And SMS Follow-Up of An Empowerment Program On Quality of Life And Fatigue In Patients With Chronic Obstructive Pulmonary Disease: A Three- Month RCT-Follow-Up Study
}

\author{
Parisa Fathizadeh Dehkordi \\ Shahrekord University of Medical Sciences \\ Haydeh Haidari ( $\nabla$ haydehheidari@gmail.com ) \\ Shahrekord University of Medical Sciences \\ Reza Masoudi \\ Shahrekord University of Medical Sciences \\ Morteza Sedhi \\ Shahrekord University of Medical Sciences \\ Fereydoon Khajeali \\ Shahrekord University of Medical Sciences
}

\section{Research Article}

Keywords: Empowerment, Follow-up, Fatigue, Quality of life, Chronic obstructive pulmonary disease

Posted Date: December 20th, 2021

DOI: https://doi.org/10.21203/rs.3.rs-1104652/v1

License: (9) (1) This work is licensed under a Creative Commons Attribution 4.0 International License. Read Full License 


\section{Abstract}

Background: Due to their debilitating and progressive conditions, chronic obstructive pulmonary diseases (COPD) can reduce patients' quality of life (QOL) and cause fatigue. This study aimed to compare the effect of telephone and SMS follow-up of an empowerment program on QOL and fatigue in patients with COPD.

Methods: This non blind randomized clinical trial (RCT) study was conducted on 105 patients with COPD in 2016-2017 in Shahrekord city. First, the pulmonary empowerment program was implemented for six 90-min sessions. Then, the patients were randomly assigned to three control, telephone follow-up, and SMS follow-up groups (35 individuals in each group) using a random number table. Data were collected in the first and the sixth sessions of the empowerment program and at the end of the follow-up period by demographic, QOL, and fatigue questionnaires. Eventually, they were analyzed through correlation coefficient and analysis of variance (ANOVA) tests using SPSS software (Ver. 20).

Results: The study results on QOL showed that the groups were not significantly different before and after the empowerment $(p>0.05)$. However, they were statistically significant differences were observed between the groups at the end of the quarterly follow-up period ( $p<$ 0.001). ANOVA results for fatigue indicated no statistically significant differences between the groups before and after the empowerment ( $p$ $>0.05)$. The three groups were not significantly different after the intervention $(p=0.05)$.

Conclusion: Based on the results, it is recommended to utilize follow-up as an important principle in empowerment using various technology methods and design more comprehensive empowerment to reduce patient fatigue.

Trial registration: Iran National Committee for Ethics in Biomedical Research (IR.SKUMS.REC.1398.104) and the Iranian Registry of Clinical Trials (IRCT20170122032101N4) (6/4/2020).

\section{Background}

Due to their debilitating and progressive pulmonary conditions, COPD can lead to physical limitations, mental disorders, and economic burden on patients and their families (1). The number of COPD patients is estimated at 328 million worldwide and is predicted to increase by $30 \%$ in the next decade, becoming the third cause of death globally in 2030. A 6.2\% COPD incidence rate is estimated among Asian people, and this rate is reported to be $1-40 \%$, with an average of $10 \%$ among Iranians based on the climatic conditions of the living area (2, 3). Long-term progressive airway obstruction leads to dyspnea, muscle atrophy, physical unpreparedness, social isolation, and weight loss, which together result in progressive atony and decreased quality of life (QOL) in these patients (4).

Fatigue is also frequently seen in these patients experienced by almost half of the patients. Nevertheless, it is often overlooked despite its high prevalence and important effects, including impaired QOL and increased risk of hospitalization $(5,6)$.

The vast majority of medications cannot completely treat the disease. Hence, symptomatic treatment aims to prevent the disease exacerbation and to empower the patient $(7,8)$. In this regard, the empowerment program is a strategy that can replace the conventional education and approach (9). Despite the critical role of empowerment its numerous uses, little attention has been paid to all its dimensions in managing such diseases as COPD (10).

Continuous patient follow-up is required to achieve positive outcomes in disease management. Therefore, in chronic diseases, the World Health Organization (WHO) recommends making patients continuously available for face-to-face visits and other means of telecare $(11,12)$.

Mobile phones are an important subset of e-health that can be used to increase the quality of care while reducing costs (13). Although the two telephone and SMS methods are similar, they are completely separate such that completely different results have been reported by using these interventions (14).

The patient can be trained using the two telephone and SMS methods, and the nurse can identify patients' problems and provide them with appropriate solutions (14-16).

Although telephone and SMS follow-up effects were investigated previously in other diseases $(17,18)$, no study has been conducted on COPD patients.

Given the high prevalence of COPD, its socioeconomic burden, and the need for patient empowerment, In the current study we tested the hypothesis the effects of empowerment and then follow-up by telephone and SMS to compare these two methods on QOL and fatigue in patients with COPD. 


\section{Methods}

Study design: This non blind randomized clinical trial study aimed to compare the effect of telephone and SMS follow-up of an empowerment program on QOL and fatigue in patients with COPD.

Participants: This study was conducted on the control group after obtaining the code of ethics (IR.SKUMS.REC.1398.104) and IRCT20170122032101N4 (6/4/2020). The research population included patients with COPD admitted to Kashani and Hajar hospitals and physicians' offices in 2019. A sample size of 35 subjects in each group was calculated using the following formula:

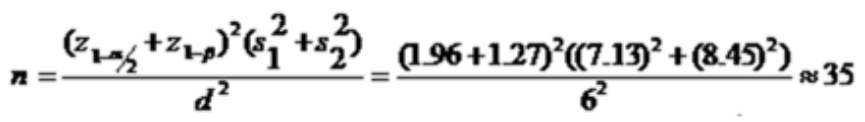

Inclusion criteria were diagnosis of COPD grades 2 and 3 according to GOLD criteria (19), willingness to participate, ability to speak and communicate, the absence of hearing problems, literacy, having mobile and landline numbers, patient's ability to use SMS, age over 40 years (20), no participation in other empowerment programs during the last 6 months, and no history of the mental disorder according to the medical record and the physician's comment. The exclusion criteria included reluctance to continue participation, patient unavailability for 2 weeks or more, diseases making the patient unstable, and absence of more than 2 sessions in empowerment sessions (21).

Data collection: The research tools included a demographic information form (age, gender, smoking status, duration of disease, BMI, and literacy status), the St. George's Respiratory Questionnaire (SGRQ) for COPD patients' QOL, and the Standard Piper Fatigue Scale (PFS). For QOL, the SGRQ has three dimensions of symptoms, activity, and effectiveness, with a total of 17 questions. The symptom subscale has eight questions that measure cough, dyspnea, sputum, wheezing, and the number of recurrent attacks. The activity subscale contains two questions that examine the dyspnea-inducing physical activities or the effects of dyspnea on daily activities. The impact dimension includes seven questions and measures the disease's effect on one's social and emotional functioning. Each subscale of the questionnaire and its total score are a number between 0 and 100, indicating the best and the worst states of QOL. The Iranian version of this questionnaire was validated ( $\mathrm{a}=0.93$ ) by Tafti et al. (2007) (2), and its reliability was calculated in the present study (0.82). The PFS, covering behavioral, emotional, perceptual, and cognitive dimensions, consists of 26 sentences. Of these sentences, 22 ones are scored in the range of 0-10 according to the severity of the signs. Scores of 0 and 10 indicate the lowest and the highest severities of the intended sign, respectively. Finally, the fatigue severity is obtained by summing the numbers selected by the patient and dividing the product by 22 as follows: 0 (nonfatigued), 1-3 (mild), 4-6 (moderate), and 4-7 (severe). Its validity was confirmed in a study by Khairi et al. (22), and its reliability was determined by Cronbach's alpha (0.91) in this study.

Intervention: Sampling was continued until achieving a total of 105 people. The empowerment program was started by obtaining informed consent from patients and coordination with the management, security, and audio-visual management of Hajar Hospital. The researcher held the program using lectures, questions/answers, and video projectors at Hajar Hospital twice a week, each lasting 90 min. The empowerment program used here was designed in line with the methods presented by Disler et al. (2016) (23) to empower patients with COPD.

At the start of the first session, the questionnaires were completed and returned to the researcher. During the empowerment sessions, an educational brochure was provided to all patients. The questionnaires were completed for the second time at the end of the sixth session. Afterward, the patients were assigned to three control, experimental one (telephone follow-up), and experimental two (SMS follow-up) groups using a random number table by the researcher. Numbers 1-105 prepared in the sixth session of each group were divided among the participants so that each subject was given a unique number. At the end of the empowerment program for all patients, each subject was included in one of the three groups according to the table of random numbers by the researcher. Blinding was not possible as each patient knew the type of follow-up intervention.

For 3 months (12), the researcher performed follow-ups were using landline and SMS service, and the control group received routine care. This stage of the study coincided with the COVID-19 epidemic. In the first month, the patients were followed up by telephone as 2 calls and then one call per week. For SMS follow-ups, pre-designed SMS as two SMS per week were sent in the first month and then one SMS per week.

Data analysis: At the end of the follow-up period, data were collected by demographic questionnaires, SGRQ for QOL, and PFS by someone other than the researcher and analyzed by SPSS 22 software using inferential and descriptive statistics (ANOVA and Correlation test) at a significance level of $<0.05$ in all tests. 


\section{Results}

Patient recruitment and enrolment were started in August 2019 and ended in April 2020 ahead of schedule due to the Covid-19 pandemic). 105 patients enrolled and at the end of empowerment sessions assigned to three group $(n=35)$. Fortunately there was not any lost in patients number follow up period!

The comparison of groups revealed that the three groups were homogeneous in terms of demographic variables (Table 1). The findings indicated that the average QOL after empowerment did not change significantly in all the groups(p > 0.05); however, the QOL of patients improved after 3 months of follow-up $(p<0.001)$ (Table 2). Examining the collected data showed that patients' fatigue did not decrease significantly after empowerment, but it decreased after the follow-up period with no statistical significance $(p=0.05)$.

Table 1

Demographic variables in three groups

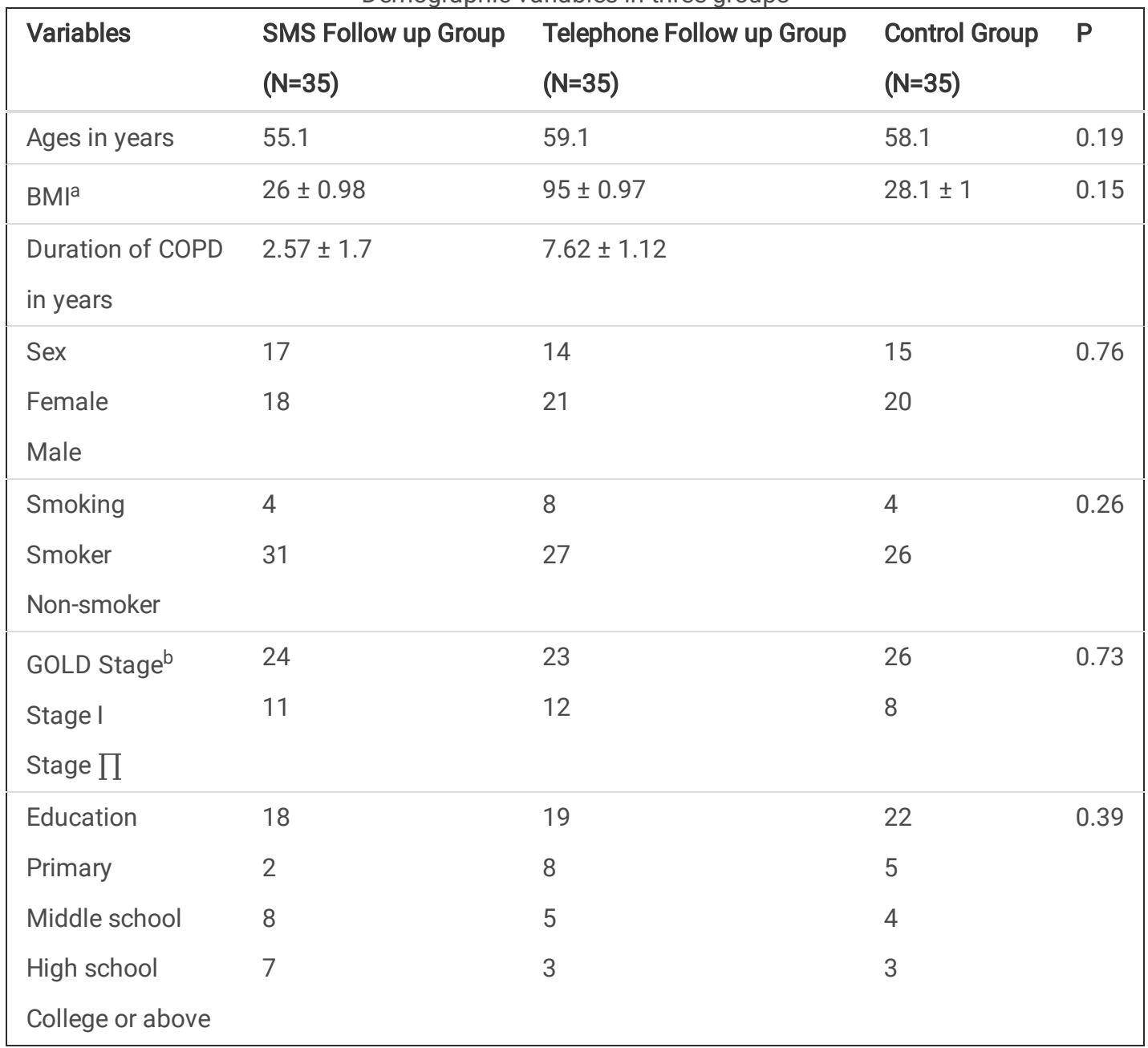


Table 2

The quality of life and fatigue variables in three groups and three stages of research

\begin{tabular}{|c|c|c|c|c|c|c|c|c|c|c|}
\hline & \multicolumn{2}{|c|}{$\begin{array}{l}\text { Before } \\
\text { empowerment }\end{array}$} & \multicolumn{2}{|c|}{$\begin{array}{l}\text { After six } \\
\text { sessions of } \\
\text { empowerment }\end{array}$} & \multicolumn{2}{|c|}{$\begin{array}{l}\text { After } 3 \text { months } \\
\text { of follow-up }\end{array}$} & \multicolumn{2}{|c|}{$\begin{array}{l}\text { Mean changes in QOL before } \\
\text { intervention }\end{array}$} & \multicolumn{2}{|c|}{$\begin{array}{l}\text { Mean changes in fatigue } \\
\text { before intervention }\end{array}$} \\
\hline & $\begin{array}{l}\text { Fatigue } \\
( \pm \text { SD) }\end{array}$ & $\begin{array}{l}\text { QOL } \\
( \pm \\
\text { SD) }\end{array}$ & $\begin{array}{l}\text { Fatigue } \\
( \pm \text { SD) }\end{array}$ & $\begin{array}{l}\text { QOL } \\
( \pm \\
\text { SD })\end{array}$ & $\begin{array}{l}\text { Fatigue } \\
( \pm S D)\end{array}$ & $\begin{array}{l}\text { QOL } \\
( \pm \\
\text { SD) }\end{array}$ & $\begin{array}{l}\text { After } \\
\text { empowerment } \\
\text { (SD) }\end{array}$ & $\begin{array}{l}\text { After } \\
\text { intervention } \\
\text { (SD) }\end{array}$ & $\begin{array}{l}\text { After } \\
\text { empowerment } \\
\text { (SD) }\end{array}$ & $\begin{array}{l}\text { After } \\
\text { intervention } \\
\text { (SD) }\end{array}$ \\
\hline $\begin{array}{l}\text { SMS } \\
\text { Follow-up } \\
\text { Group }\end{array}$ & $\begin{array}{l}4.5 \pm \\
2.17\end{array}$ & $\begin{array}{l}34.78 \\
\pm 1.4\end{array}$ & $\begin{array}{l}4.12 \pm \\
2.32\end{array}$ & $\begin{array}{l}28.23 \\
\pm \\
1.37\end{array}$ & $\begin{array}{l}3.72 \\
\pm 2.06\end{array}$ & $\begin{array}{l}20.87 \\
\pm \\
7.36\end{array}$ & $-6.55 \pm 1.63$ & $\begin{array}{l}-14.15 \pm \\
1.78\end{array}$ & $-0.39 \pm 0.19$ & $-22.1 \pm 0.26$ \\
\hline $\begin{array}{l}\text { Telephone } \\
\text { Follow-up } \\
\text { Group }\end{array}$ & $\begin{array}{l}3.62 \pm \\
2.42\end{array}$ & $\begin{array}{l}29.69 \\
\pm \\
1.27\end{array}$ & $\begin{array}{l}3.42 \pm \\
2.42\end{array}$ & $\begin{array}{l}25.50 \\
\pm \\
1.03\end{array}$ & $\begin{array}{l}2.84 \pm \\
2.34\end{array}$ & $\begin{array}{l}19.54 \\
\pm \\
8.13\end{array}$ & $-4.1 \pm 18.14$ & $\begin{array}{l}-10.14 \pm \\
1.35\end{array}$ & $-0.21 \pm 0.13$ & $-0.77 \pm 0.17$ \\
\hline $\begin{array}{l}\text { Control } \\
\text { Group }\end{array}$ & $\begin{array}{l}4.7 \pm \\
2.06\end{array}$ & $\begin{array}{l}37.38 \\
\pm \\
1.39\end{array}$ & $\begin{array}{l}4.09 \pm \\
1.84\end{array}$ & $\begin{array}{l}27.57 \\
\pm \\
1.02\end{array}$ & $\begin{array}{l}4.07 \pm \\
1.94\end{array}$ & $\begin{array}{l}27.87 \\
\pm \\
1.10\end{array}$ & $-4.80 \pm 4.46$ & $-4.50 \pm 1.76$ & $-0.60 \pm 0.18$ & $-0.62 \pm 0.21$ \\
\hline$P^{*}$ & 0.05 & 0.29 & 0.32 & 0.56 & 0.10 & 0 & 0.48 & 0 & 0.25 & 0.13 \\
\hline
\end{tabular}

\section{Discussion}

This study showed that empowerment without follow-up did not significantly influence the improvement in patient's QOL and fatigue. After the follow-up period, SMS follow-up had the greatest effect on QOL, but follow-ups did not significantly affect the improvement of fatigue.

In the present study, patients in the three groups receiving the empowerment program were not significantly different regarding QOL and fatigue. This result disagrees with Moazani et al. (2020) (24), probably due to the lack of face-to-face sessions at home in our study or different types of interventions during empowerment.

In agreement with our results, ayora et al. presented evidence that training and telephone follow-up could improve the total QOL score (25). However, training on disease exacerbation was only a part of it and improved the total QOL score by follow-up. Consistent with the present study, another work reported the effect of telephone counseling on the QOL of patients after coronary artery bypass graft surgery (26). However, the present study is inconsistent with other studies conducted on QOL. For instance, a study compared telephone and SMS followups in increasing the QOL of patients after heart valve replacement and concluded that these two methods were equally effective (18). This study is different from ours because SMS intervention was more effective than the telephone in the present study, probably regarding the difference between the study population and the number of samples. In a three-group clinical trial study, Jalali et al. concluded that SMS follow-up could effectively improve the QOL of these patients, but routine and telephone follow-up had no significant impacts (14). Their study disagrees with our research regarding the ineffectiveness of telephone follow-up on QOL, although SMS follow-up was more effective than the telephone in the present study. This inconsistency may be attributed to the lack of a clear and continuous protocol and untargeted telephone calls in the study of Jalali et al.

A study claimed that home-based pulmonary rehabilitation was more effective in reducing patients' fatigue than QOL (19), which is inconsistent with the present study, possibly due to differences in the follow-up duration.

Clearly, the simple traditional training could not change patients' behavior and motivation for recovery. Nevertheless, as a dynamic and comprehensive process, empowerment can be very helpful regarding its positive effect on patients' QOL in other diseases such as stroke, hypertension, and diabetes (27). However, according to the present study, the empowerment results will not be significantly positive on patients' QOL until all these factors are used together. This finding reflects the important and serious effect of telecare, as its neglect can even lead to failure in improving patients' QOL. Among the means of telecare, telephone and mobile are more accessible and widely used than other means. Overall, the use of these measures as telenursing care improves the quality of nursing services and reduces traffic and patients' travel expenses, in addition to helping in patients' health improvement (28).

Fatigue is also a multidimensional symptom with three possible causes of systemic, behavioral, and psychophysical general categories (29). Accordingly, fatigue is a complex variable with great importance in patients' lives. Its effectiveness and improvement require designing multidimensional (physiological, behavioral, and psychological) and personalized interventions; even the type of exercise can also influence the effectiveness of the intervention. Another critical factor in fatigue rate is the fear of activity due to the fear of pain or injury, referred to as kinesiophobia in psychology. A patient may suffer from it and refuse to express this problem. Because kinesiophobia is closely related to the 
patient's fatigue (30), some of the patients in the present study might have experienced some degree of kinesiophobia and refused to talk to the researcher about it. It is of note that the follow-up phase in this study coincided with the COVID-19 epidemic, which might have affected the ineffectiveness of follow-up on patients' fatigue.

A strength of this study includes the type of research as a three-group clinical trial along with the design of an empowerment program, which has rarely been done in other studies. In contrast, a limitation of this study is the withdrawal of illiterate subjects and those with grade 4 COPD from the study, which prevents its generalization but the empowerment program is usable for all grades of patients.

\section{Conclusion}

Overall, it can be concluded that patients need a comprehensive empowerment program with follow-up to improve their QOL, and patients' fatigue is a very complex complication that requires further comprehensive studies. Future studies are recommended to investigate the effect of empowerment of patients with COPD using various sports such as water sports and Tai chi, use monitoring devices while following up this group of patients, and utilize technology for empowerment. This approach can help include grade 4 patients in the program and can also be used for all pulmonary patients in the COVID-19 conditions.

\section{Abbreviations}

COPD: chronic obstructive pulmonary diseases- QOL: quality of life - SMS: Short Message Service

\section{Declarations}

Availability of data and materials The datasets analyzed during the current study are available from the corresponding author on reasonable request.

Acknowledgments: This article was extracted from a master's thesis (code 3115) approved by Shahrekord University of Medical Sciences. Thus, the authors appreciate the cooperation of relevant officials and also we wish to thank all patients included in this project for their trust and participation.

Authors' contributions: $\mathrm{PF}, \mathrm{HH}$ and RM were responsible for the conception of the project. PF was responsible for screening, patient tracking and administration, empowerment plan and follow up.MS was responsible for statistical analyses. FKH and PF were responsible for designing the empowerment program. All authors read and approved the final manuscript

Competing interests: The author(s) declared no potential conflicts of interest concerning this article's research, authorship, and publication.

Ethical approval: The study was approved by the Iran National Committee for Ethics in Biomedical Research (IR.SKUMS.REC.1398.104) and the Iranian Registry of Clinical Trials (IRCT20170122032101N4) (6/4/2020)..

Funding: his work was supported by Shahrekord University of Medical Sciences Funding included the cost of devices (telephone calls and SMSs) and some working hours.

ORCID iD: Parisa Fathizadeh Dehkordi https://orcid.org/0000-0003-1303-0498

\section{References}

1. Baker E, Fatoye F. Patient perceived impact of nurse-led self-management interventions for COPD: A systematic review of qualitative research. Int J Nurs Stud [Internet]. 2019;91:22-34. Available from: https://doi.org/10.1016/j.ijnurstu.2018.12.004

2. Shariati A, Eidani E, Goharpei S, Latifi M, Bavarsad MB. Surveying the Effect of Inspiratory Muscle Training on Quality of Life in COPD Patients. Jundishapur Sci Med J. 2012;11(4):59-68 [PERSIAN].

3. Nguyen ha T, Collins PF, Pavey T g, Nguyen nhung V, Pham TD, Gallegos D I. Nutritional status, dietary intake, and health- related quality of life in outpatients with COPD. Int J COPD. 2019;14:215-26.

4. Lan C, Yang M, Huang H, Wu C, Su W-L, Tzeng I-S, et al. Serial changes in exercise capacity, quality of life and cardiopulmonary responses after pulmonary rehabilitation in patients with chronic obstructive pulmonary disease. Hear Lung [Internet]. 2018;47:477-84. Available from: https://doi.org/10.1016/j.hrtlng.2018.06.006

5. Seyedi Chegeni P, Gholami M, Azargoon A, Hossein Pour AH, Birjandi M, Norollahi H. The effect of progressive muscle relaxation on the management of fatigue and quality of sleep in patients with chronic obstructive pulmonary disease: A randomized controlled clinical 
trial. Complement Ther Clin Pract [Internet]. 2018;31:64-70. Available from: https://doi.org/10.1016/j.ctcp.2018.01.010

6. Kouijzer M, Brusse-keizer M, Bode C. COPD-related fatigue: Impact on daily life and treatment opportunities from the patient s perspective. Respir Med [Internet]. 2018;141:47-51. Available from: https://doi.org/10.1016/j.rmed.2018.06.011

7. Pedersen PU, Ersgard KB, Soerensen TB, Larsen P. Effectiveness of structured planned post discharge support to patients with chronic obstructive pulmonary disease for reducing readmission rates: a systematic review. JOANNA BRIGGS Inst. 2017;2060-86.

8. Perkins-porras L, Riaz M, Okekunle A, Zhelezna S, Chakravorty I, Ussher M. Feasibility study to assess the effect of a brief mindfulness intervention for patients with chronic obstructive pulmonary disease: A randomized controlled trial. Chron Respir Dis. 2018;15(4):40010.

9. Razzazan N, Ravanipour M, Gharibi T, Motamed N, Zarei A reza. Effect of self-management empowering model on the quality of life in adolescents and youths with major thalassemia. J Nurs Educ. 2014;3(2):48-59(persian).

10. Fotokian Z, Mohammadi Shahboulaghi F, Fallahi-khoshknab M. The empowerment of elderly patients with chronic obstructive pulmonary disease: Managing life with the disease. PLoS One. 2017;12(4):e0174028.

11. Sorur J iFard, Ghodsbin F, Kaviani MJ, Jahanbin I, Bagheri Z. The Effect of Follow up (Telenursing) on Liver Enzymes in Patients with Nonalcoholic Fatty Liver Disease: A Randomized Controlled Clinical Trial. IJCBNM. 2016;4(3):239-46.

12. Zolfaghari M, Mousavifar SA, Pedram S, Haghani $H$. The impact of nurse short message services and telephone follow-ups on diabetic adherence:which one is more effective? J Clin Nurs. 2012;21:1922-31.

13. Dorri S, Asadi F, Olfatbakhsh A, Kazemi A. A Systematic Review of Electronic Health (eHealth) interventions to improve physical activity in patients with breast cancer. Breast Cancer [Internet]. 2020;27(1):25-46. Available from: https://doi.org/10.1007/s12282-019-00982-3

14. Jalali R, Hoseinpour A, Menati L, Amini M. The Effect of Three Methods of Follow-up (Short Message Service SMS, Telephone and Regular) on the Quality of Life in Heart Failure Patients. Futur Med Educ J Introd. 2018;8(1):11-6.

15. Dikopoulos N, Mayr M, Neu B, Hann A. Improving the quality and acceptance of colonoscopy preparation by reinforced patient education with short message service: results from a randomized, multicenter study (PERICLES-II) Study design. Gastrointest Endosc [Internet]. 2018;1-8. Available from: https://doi.org/10.1016/j.gie.2018.08.014

16. Newton L, Sulman C. Use of text messaging to improve patient experience and communication with pediatric tonsillectomy patients. Int J Pediatr Otorhinolaryngol [Internet]. 2018;113:213-7. Available from: https://doi.org/10.1016/j.ijporl.2018.07.048

17. Ove S, Moons P, Sandvik L, Leegaard M, Solheim S, Tønnessen T, et al. Impact of telephone follow-up and 24 / 7 hotline on 30-day readmission rates following aortic valve replacement -A randomized controlled trial. Int J Cardiol [Internet]. 2019;(xxxx). Available from: https://doi.org/10.1016/j.ijcard.2019.07.087

18. Sadeghi shermeh M, Ghafouri F, Tadrisi SD, Tayyebi A. The effect of follow-up care by telephone and short massage services on patient's quality of life after cardiac valve replacement surgery. Iran J Crit Care Nurs. 2013;6(1):65-72.

19. Jokar Z, Mohammadi F, Khankeh H, Fallah Tafti S, Koushesh F. Comparing Home-based Pulmonary Rehabilitation Nursing on Fatigue and quality of life in Patients with COPD. J Fasa Univ Med Sci. 2014;4(2):168-176 [PERSIAN].

20. Nascimento ESP do, Malosá LM, Dias FDFSP, Greiffo FR, De APL, Stirbulov R, et al. Home-based pulmonary rehabilitation improves clinical features and systemic inflammation in chronic obstructive pulmonary disease patients. Int J COPD. 2015;10:645-53.

21. Moein M, Aghajani M, Mirbagher Ajorpaz N, Khorasanifar L. Effect of an Empowerment Program on Self-Efficacy of Patients With Type 2 Diabetes. Iran Red Crescent Med J. 2017;19(1):e29252.

22. Khayeri F, Rabiei L, Shamsalinia A, Masoudi R. Effect of Fordyce Happiness Model on depression, stress, anxiety, and fatigue in patients with multiple sclerosis. Complement Ther Clin Pract [Internet]. 2016;25:130-5. Available from:

http://dx.doi.org/10.1016/j.ctcp.2016.09.009

23. Disler RT, Appleton J, Smith TA, Hodson M, Inglis SC, Donesky D, et al. Empowerment in people with COPD. Patient Intell. 2016;8:7-20.

24. Moazeni SS, Ghaljeh M, Navidian A. The Effect of Pulmonary Rehabilitation on Fatigue and Quality of Life in Patients with Chronic Obstructive Pulmonary Disease: A Quasi-Experimental Study. Med Surg Nurs J. 2020;9(1):e103899.

25. Folch-ayora A, Orts-cortés MI, Macia-soler L, Andreu-guillamon M V, Moncho J. Patient Education and Counseling Patient education during hospital admission due to exacerbation of chronic obstructive pulmonary disease: Effects on quality of life - Controlled and randomized experimental study. Patient Educ Couns [Internet]. 2019;102(3):511-9. Available from:

https://doi.org/10.1016/j.pec.2018.09.013

26. Bikmoradi A, Masmouei B, Ghomeisi M, Roshanaei G. Patient Education and Counseling Impact of telephone counseling on the quality of life of patients discharged after coronary artery bypass grafts. Patient Educ Couns [Internet]. 2017; Available from:

http://dx.doi.org/10.1016/j.pec.2017.06.010

Page $7 / 8$ 
27. Wu Y, Zhang L, Peng X. Current Status of the Application of the Empowerment Theory in Patients with Chronic Obstructive Pulmonary Disease. Yangtze Med. 2019;3:212-24.

28. Ghoulami-shilsari F, Esmaeilpour Bandboni M. Tele-Nursing in Chronic Disease Care: A Systematic Review. Jundishapur J Chronic Dis Care. 2019;8(2):e84379.

29. Agust A, Dekhuijzen PNR. Fatigue in COPD: an important yet ignored symptom. In: . 2017. p. 542-4.

30. Vardar-yagli N, Calik-kutukcu E, Saglam M, Inal-ince D, Arikan H, Coplu L. The relationship between fear of movement, pain and fatigue severity, dyspnea level and comorbidities in patients with chronic obstructive pulmonary disease. Disabil Rehabil [Internet]. 2018;DOI: 10.1080/09638288.2018.1459886. Available from: https://doi.org/10.1080/09638288.2018.1459886

\section{Figures}

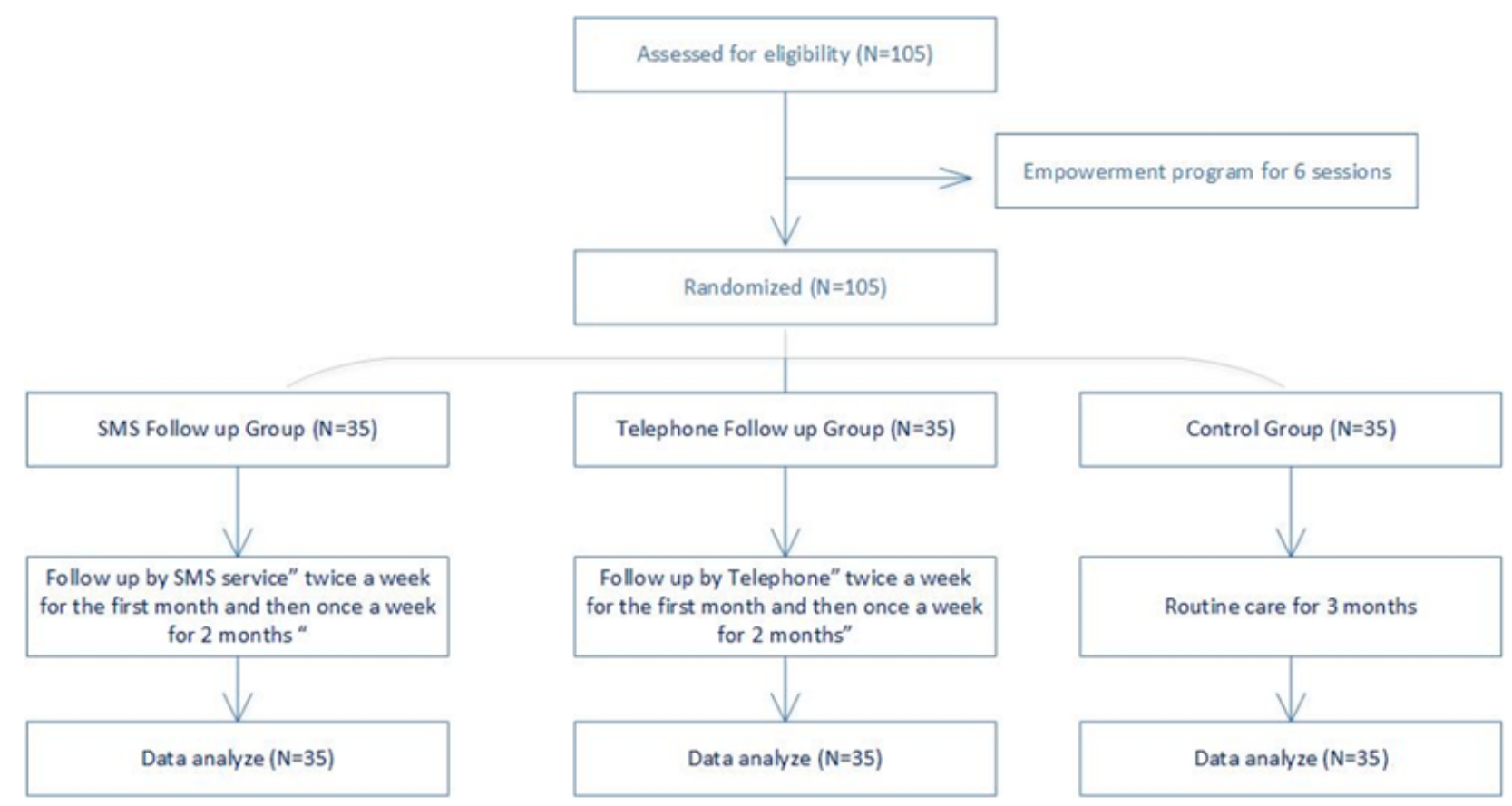

\section{Figure 1}

The flowchart of this study

\section{Supplementary Files}

This is a list of supplementary files associated with this preprint. Click to download.

- Supplementary.docx 